\title{
El Estado y la teoría literaria: hacia una agenda de investigación
}

The State and Literary Theory: Toward a Research Agenda

O Estado e a teoria literária: para uma agenda de investigação

\section{Gregory J. Lobo}

UNIVERSIDAD DE LOS ANDES, BOGOTÁ, COLOMBIA

Profesor Asociado del departamento de Lenguajes y Estudios

Socioculturales de la Universidad de los Andes, Bogotá. PhD

Literatura en University of California, Davis. Ha publicado

numerosos artículos en revistas especializadas y el libro Colombia:

Algo diferente de una nación (CESO, Universidad de los Andes,

2009). Correo electrónico: globo@uniandes.edu.co

Documento accesible en línea desde la siguiente dirección: http://revistas.javeriana.edu.co doi:10.11144/Javeriana.CL19-37.eetl 


\section{Resumen}

Si bien la relación entre la literatura y el sujeto nacional ha sido durante algún tiempo un foco importante para la investigación en los estudios literarios, el análisis de la relación entre la obra literaria y lo que elaboro como subjetividad estatal [state subjectivity] está poco desarrollado, por decirlo así. Empleando un marco interdisciplinario, esbozo aquí una manera de conceptualizar el Estado en relación con los sujetos y en relación con el sistema mundial capitalista, que creo que será fructífera para la investigación sobre la producción literaria de la subjetividad estatal. Concluyo con una ejemplificación de mi argumento sobre el estado que se centra en el caso de Chile.

Palabras clave: estado; nación; teoría literaría; Chile; subjetividad

\section{Abstract}

While the relationship between literature and the national subject has for some time been an important focus for research in literary studies, analysis of the relation between literary work and what I elaborate as State subjectivity is, so to speak, under developed. Using an interdisciplinary framework, I outline here a way to conceptualize the State in relation to subjects and in relation to the capitalist world system, that I believe will be fruitful for research into the literary production of State subjectivity. I conclude with an exemplification of my argument about the State that focuses on the Chilean case.

Keywords: State; Nation; literary theory; Chile; subjectivity

\section{Resumo}

Embora a relação entre a literatura e o sujeito nacional tenha sido durante algum tempo um foco importante para a investigação no campo dos estudos literários, a análise da relação entre obra literária e o que elaboro como "subjetividade estatal" [state subjectivity] está pouco desenvolvida, por assim dizer. Empregando um marco interdisciplinar, esboço aqui uma maneira de conceituar o Estado em sua relação com os sujeitos e com o sistema mundial capitalista que creio que será frutífera para a pesquisa sobre a produção literária da subjetividade estatal. Concluo com uma exemplificação de meu argumento sobre o Estado que se centra no caso do Chile.

Palavras-chave: Estado; nação; teoria literária; Chile; subjetividade

\section{Cómo citar este artículo:}

Lobo, Gregory. "El Estado y la teoría literaria: hacia una agenda de investigación". Cuadernos de Literatura 19. 37 (2015): 20-37. doi:10.11144/Javeriana.CL19-37.eetl 


\section{Introducción}

La proliferación de naciones como resultado no sólo de la descolonización después de la Segunda Guerra Mundial, sino, de nuevo, siguiendo la implosión de la Unión Soviética, parecería sugerir que las comunidades a las que llamamos naciones no sean imaginadas sino reprimidas - reprimidas hasta el día en que puedan ellas también reivindicar su estatalidad como su derecho, su modo formal y oficial de auto reconocimiento y de representarse en su particularidad ante y entre el sistema universal de Estados-naciones-. En la medida en que estas naciones emergentes sólo han podido estructurarse de manera más o menos duradera al optar por economías neo-liberales, o más sencillamente, capitalistas, es apropiado proponer la siguiente fórmula: las naciones parecerían ser singularidades colectivas reales que requieren sin embargo del Estado para garantizar su realidad; y esta entidad combinada, el Estado nacional, se sostiene mejor por medio de una economía esencialmente capitalista.

Esta lógica, por supesto, es problemática, como cualquier lector de Anderson sabrá, dado que la premisa - la realidad o sustancialidad del colectivo nacional - no se puede sostener. La nación no es objetivamente real sino imaginada y necesita constantemente construcción y reconstrucción simbólica (lingüística, ideológica, discursiva). Una mejor fórmula para relacionar los tres términos - economía, Estado y nación - no procede de la premisa de la sustancialidad de este concepto (la nación), sino de la idea según la cual el capitalismo es un proceso sistémico global real del cual todo lo demás parte. El capitalismo - por lo menos el capitalismo con el cual el planeta se ha encontrado encartado aproximadamente durante los últimos doscientos años- no puede funcionar sin los Estados, los cuales hacen lo que el capitalismo no puede hacer: producir y mantener orden político. Los Estados pueden hacer esto porque disponen, como lo señaló Weber, de los medios de violencia. No obstante, los Estados sólo pueden disponer de los medios de violencia continuamente, en la medida en que este disponer pueda justificarse en términos del interés de la nación. Más precisamente, en términos del interés del grupo social que apodera al estado para que actúe (Arendt). Si al capitalismo le hace falta el Estado, al Estado le hace falta la nación - la idea de la nación- para justificar su dominio.

Hay, entonces, una diferencia conceptual muy importante entre el Estado y la nación que sugiere que habrá una diferencia muy importante entre el sujeto de la nación y el sujeto del Estado, entre la subjetividad nacional y la subjetividad estatal. La diferencia consiste en lo siguiente: el sujeto nacional puede o no identificarse con el Estado, puede o no ser un sujeto del Estado. Lo que quiero señalar aquí es que esta diferencia no es simplemente conceptual, es, de hecho, 
real y visible en el conflicto entre sujetos nacionales que tienen ideas diferentes y conflictivas sobre el carácter del Estado de un país, sobre qué debería hacer el Estado. Uno podría pensar, por ejemplo, en el período de McCarthyism en Estados Unidos, y las audiencias de la House Committee on un-American Activities, en las que estadounidenses que se indentificaban con la nación, pero no con el Estado, fueron persiguidos por sujetos más propiamente interpelados por el Estado. Uno también podría pensar en los nacionales cubanos, no todos están igualmente enamorados del Estado cubano. Y por supuesto, la crisis actual en Venezuela se ofrece para un estudio en tiempo real sobre cómo dos grupos de nacionales pueden oponer sus ideas sobre el Estado con secuelas incluso mortales. Devolviendo el reloj una vez más, se podría pensar en Chile, donde el carácter del Estado que se iba cambiando bajo el régimen de Allende provocó una gran desidentificación con dicho Estado y el acogimiento de otro tipo de Estado, tan asesino como fuera. Se podría decir algo parecido sobre muchos países latinoamericanos; tendré más que decir sobre Chile más adelante.

¿Cómo se siente ser un sujeto estatal? Ser un sujeto del Estado es sentirse sometido al Estado, conscientemente o no. Es afirmar o por lo menos aceptar la autoridad y la legitimidad de un Estado. Este sentimiento, esta actitud es solicitada; esta subjetividad es interpelada (Althusser, 2005) en múltiples niveles a través de todo lo que solemos llamar cultura, no sólo en novelas y películas: periódicos, televisón, y hoy en día también en internet. Es decir, la cultura opera no sólo para producir los lazos afectivos de la comunidad nacional (Sommer) sino que además crea un lazo - un sometimiento - afectivo entre sujeto y Estado. Por supuesto, no todos serán sumisos o sometidos — los sujetos "malos" son endémicos en cualquier proyecto socializador- pero sí suficientes personas. Ser sumiso ante la autoridad del Estado es consentir la dominación propia día tras día. Es ser pasivo o estar de acuerdo con la violencia del Estado practicada contra los individuos y los grupos que ya no consientan a consentir. Uno se somete al estado de la violencia en su forma cotidiana y notoria, como si el estado de violencia fuera el Estado de derecho.

Considero que los estudios literarios no se han enfocado lo suficiente en la producción de los sujetos estatales. La construcción literaria de los sujetos de la nación es un área clave de investigación y lo ha sido durante bastante tiempo, pero el estudio de los sujetos encarnados individualmente - que se conciben como reconocidos por el Estado que ejerce la autoridad última sobre la naciónse encuentra más o menos ausente del escenario. El análisis y la crítica de las fantasías nacionales de la literatura han abandonado, han dejado sin tocar la 
agencia que depende de la nación por su cobertura ideológica ${ }^{1}$ como su origen y fuente legimitadora. Si la distinción entre la subjetividad nacional y estatal es sólida, el análisis político de la literatura necesita investigar el papel de los productos literarios en la generación de sujetos del Estado, lo cual es, simultáneamente, investigar qué significa ser un sujeto estatal. Antes de que esto pueda suceder, sin embargo, la teoría literaria debe adumbrar una teoría del Estado afín a sus propósitos.

Entonces, el propósito de este ensayo no es proporcionar un relato científico-político o político-teorético del Estado; más bien es construir un concepto del Estado que pueda impulsar el análisis de las obras literarias con relación a la producción de cierto tipo de sujeto y, por extensión, con la reproducción del capitalismo. Brevemente, entendemos el Estado en los siguientes términos: el Estado es la institución local, estructural y necesaria de la acumulación capitalista en escala mundial. ${ }^{2}$ En lo que sigue aquí, intentamos esbozar y organizar en un nivel obligatoriamente general las corrientes principales que componen la variada teoría del Estado para desconstruir este concepto ${ }^{3}$ y después ejemplificarlo con el Estado en Chile.

\section{El Estado}

Las diversas teorías del Estado pueden agruparse de manera no totalmente arbitraria bajo tres encabezados internamente heterogéneos: liberal/pluralista, autonomista, y marxista. Los liberales y los pluralistas entienden el Estado sencillamente como el Gobierno, y conceptualmente como arena en la que grupos de ciudadanos opuestos o antagónicos solucionan sus diferencias. El Estado es un terreno neutral, constituido precisamente para facilitar la resolución pacífica de los conflictos entre los actores de una sociedad. Según los autonomistas el Estado se concibe no solamente como arena en la cual, por decirlo así, la sociedad civil se resuelve, sino también como un actor por derecho propio, una instancia independiente y autónoma con respecto a la sociedad civil (Skocpol). En este orden de ideas, el Estado no es neutral, y es más, puede gestionar una

\footnotetext{
Appadurai argumenta que la nación es la "coartada ideológica del estado terriotrial" (159).

Obviamente esta formulación se alza sobre los hombros de la obra de Immanuel Wallerstein.

Es probable que lectores de Poulantzas puedan notar una semajanza con la teoría del Estado presentado por él particularmente en su debate con Miliband (cuya teoría expongo más adelante); sin embargo, en su última obra Poulantzas se distancia de una teoría general del Estado y es precisamente esto lo que creo que le hace falta a la teoría literaria. Incluso en su último trabajo Poulantzas no revela cómo el Estado puede reconstituirse históricamente como la institución local, estructural y necesaria del capitalismo global, y esto porque su análisis, básicamente estructuralista, no se concentra mucho en el sujeto individual, y mucho menos en el sujeto estatal.
} 
agenda propia sin prestarles atención a los actores y grupos por fuera. Creo que esta noción de la autonomía del Estado tiene algo de fondo pero no con el significado empleado por los autonomistas. Desarrollo este punto más adelante.

Al mismo tiempo, el marxismo ha generado un tercer modo de abordar el Estado. Ralph Miliband, por ejemplo, se une en cierto sentido a los autonomistas como Skocpol al sostener que el Estado no es nuetral. Para Miliband, no obstante, la agenda del Estado nunca es propia: es la de la clase burguesa. El Estado, según Miliband, es un instrumento, un instrumento de esta clase; por ende su visión del Estado es instrumentalista: la clase dominante utiliza el Estado para avanzar sus intereses. Esta formulación es similar si no idéntica a la de Marx y Engels en el Manifiesto del Partido Comunista: "El poder estatal moderno no es más que una junta que administra los negocios comunes de toda la clase burguesa" (26). Mientras Lenin tenía una concepción del Estado parecidamente instrumentalista, al creer que la clase obrera podría usar el Estado para avanzar sus intereses, otros marxistas, como por ejemplo Gramsci y Althusser y Poulantzas, han discutido la profunda penetración (y por ende, desde el punto de vista de los liberales y pluralistas, paradójica) del Estado en la sociedad civil; el énfasis ha sido sobre la relación con las clases, como si éstas fueran dadas de antemano, ontológicamente, en lugar de considerarse productos históricos de la práctica humana (Bourdieu).

En las siguientes páginas expongo brevemente las ideas fundamentales de los principales autores que me han ayudado a construir mis reflexiones sobre el Estado. Estas le deben mucho al pensamiento de Michael Mann y Charles Tilly, ambos con un pie en la escuela autonomista, aunque también recurro al marxista italiano Antonio Negri (quien posee un valioso trabajo antes de - y mejor queImperio con Michael Hardt). Concluyo mi presentación de la teoría del Estado con el trabajo teórico literario de Fredric Jameson y la corriente postestructuralista de las relaciones internacionales representada por David Campbell.

\subsection{Mann}

Empiezo con el artículo de Mann, "The Autonomous Power of the State: its Origins, Mechanisms and Results". Leo a Mann para entender qué quiere decir autonomía del Estado y para introducir un concepto - la utilidad social- cuya importancia profunda es evidente sólo al leer a Tilly. Lo propiamente específico del Estado, sostiene Mann, y lo que previene que se reduzca a ser un instrumento de uno o varios grupos en una formación social delimitada geográficamente es su "centralidad y terriorialidad" (1). Centralizado y ejerciendo control último

4 La traducción de las citas de los textos cuya versión castellana no he podido encontrar es mía. 
sobre todo el espacio dentro de un territorio delimitado, el Estado es, por ende, diferenciado y autónomo con respecto a todos los otros actores en la formación social en cuestión. Su autonomía se alimenta, más aún, del hecho de que tiene un "monopolio [sobre] la producción de las reglas autoritativas, respaldada por un monopolio [sobre] los medios de violencia física" (4). No obstante, lo más importante para Mann en cuanto a la autonomía del Estado es que sin un aparato estatal las sociedades no perduran. Por esta razón, según Mann, la autonomía del Estado se deriva de la necesidad de tener uno (13).

Mann desarrolla la noción del poder autónomo del Estado al unirla con de concepto de la utilidad social: "Cualquier Estado que adquiere o explota la utilidad social será provisto con apoyos infraestructurales" (26), los cuales el Estado puede emplear para sus propios fines. Como consecuencia, un Estado acumula poder para sí en la medida en que pueda llevar a cabo acciones socialmente útiles que los actores sociales no estatales no quieran llevar a cabo. Sin embargo, puesto que Mann no es claro al momento de definir la utilidad social con palabras precisas, debemos proceder al aporte de Tilly para investigar más detalladamente el concepto: ¿qué quiere decir el término y cómo ha funcionado en el desarrollo del Estado?

\subsection{Tilly}

Charles Tilly inaugura su artículo "Guerra y construcción del Estado como crimen organizado" con una analogía: "Si el negocio de la protección representa el crimen organizado en su versión más sofisticada, entonces la guerra y la construcción del Estado - paradigma del negocio de la protección con la ventaja de la legitimidad - se convierten en el mejor ejemplo del crimen organizado" (1). En otras palabras, si los funcionarios del Estado organizan protección para la población en general, ellos, y por tanto el propio Estado, actúan como extorsionadores o chantajistas "en la medida en que las amenazas frente a las que un gobierno determinado defiende a sus ciudadanos son imaginarias o son consecuencia de sus propias actividades" (3). Para Tilly es una evidencia que "los propios gobiernos con frecuencia simulan, estimulan o incluso inventan amenazas o guerras externas" ; y más aún, puesto que "las actividades de represión de los gobiernos a menudo constituyen las amenazas más importantes para sus propios ciudadanos, muchos gobiernos actúan, en esencia, del mismo modo que los chantajistas" (34).

\footnotetext{
5 He enmendado la traducción citada para que sea más fiel al orginal.
}

6 He enmendado la traducción. 
Es en este momento cuando el argumento de Tilly complementa el de Mann, al responder la pregunta por la manera en que los Gobiernos o Estados "chantajistas" adquieren la autoridad de conducirse de tal modo. Su respuesta aclara el concepto de Mann de la utilidad social. Basta decir que en algún momento "fundacional", si se quiere, aquellos que ya disfrutaban de algún grado de privilegio y poder buscaban extender su alcance inevitablemente por medio de la guerra. Siguiendo a Tilly, para poder hacer la guerra hacía falta expandir el acceso a recursos que se podían convertir en medios de hacer guerra (5). Como dice el autor: "A largo plazo, la búsqueda [por más poder] les obligó inevitablemente a permitir la actividad habitual de los acumuladores de capital que podían facilitarles crédito, y a imponer alguna modalidad de impuesto periódico a las personas y actividades que se encontraban dentro de su ámbito de control" (5). Aquí debemos notar dos cosas. Primero, existe una distinción muy clara entre los beneficiarios del Estado y aquellos que deben beneficiar al Estado. En la historia entera de la modernidad esta distinción no ha sido suprimida hasta ahora. Segundo, aquellos que benefician al Estado - aquellos que están sujetos a los impuestos - tenderían a apoyar a los poderosos en la medida en que a) los poderosos no destruyesen totalmente su modo de existencia, y b) los poderosos no permitiesen que otros hicieran algo parecido. En cuanto a aquellos que manejaban los créditos, sus intereses se alineaban con los intereses de los poderosos dado que querían recibir su dinero completo más los intereses. El capital prestado, sin embargo, tenía que acumularse antes de poderse prestar, lo cual implica que "las personas que llevaban a cabo la construcción del Estado desarrollaron un creciente interés por fomentar la acumulación de capital" (5). Esto es crucial.

Es crucial, porque así se logra entender que en la medida en que el Estado proteja y promueva la acumulación del capital puede así demostrar el índice de su utilidad social. Esto no niega lo que hemos venido diciendo sobre la autonomía del Estado. En otras palabras, el hecho de que el Estado sea útil para el burgués no implica que se vuelva la herramienta de la clase burguesa, pues como lo demuestra cualquier sociología competente, esta clase no se encuentra tan unificada como se supone. Distintas facciones querrán distintas cosas del Estado. Más bien, parece que el Estado se constituye en el agente de la acumulación del propio capital en tanto que obtiene recursos no de capitalistas particulares (relación que niega su autonomía y lo reduce a ser instrumento o herramienta), sino del capital. Así, se puede decir que su autonomía está arraigada en su capacidad de asegurar su propia reproducción, lo que a través de la historia ha dependido de su capacidad de asegurar acceso al excedente acumulado socialmente. Para 
bien o mal, históricamente, es el proceso capitalista el que mejor ha podido generar este excedente.

Volvamos a Mann brevemente para aclarar esto. Recuérdese que Mann sostiene que la autonomía del Estado reside, últimamente, en el hecho de que las sociedades no perduran sin Estados. Bien, pero "sociedad" no es un término neutral. Siempre se remite a una formación social estructurada en dominación (Althusser, 1968). En Tilly, en sus referencias por una parte a los capitalistas y por otra a los que pagan impuestos o tributo, ya se encuentra implicada la existencia de una sociedad estratificada - una economía política (en el sentido de politizada), un orden (ordenado, una jerarquía) social-. Es más, hemos visto que cada cual (el capitalista, el contribuyente) tenía intereses establecidos en la reproducción del Estado, uno para enriquecerse, el otro para sobrevivir.

Es en este momento cuando podemos hablar de sujetos del Estado, sujetos que reconocen (o mal reconocen, como diría Bourdieu) al Estado como el garante necesario de la vida y se someten más o menos libremente a su dominio. El Estado, no obstante, sólo puede reproducirse sobre la base del acceso al excedente acumulado, mientras la misma existencia de semejante excedente implica la realidad de relaciones sociales de explotación y dominación. El Estado emerge, por tanto, como garante de una sociedad estructurada en dominación y debe, inlcuso, favorecer esa relación social básica para reproducir y perpetuarse. Así, ¿los Estados necesitan al capitalismo? No. Es la formación social incipiente, una economía política primitiva en la que algunos se benefican a costa de otros, a la cual le hace falta algún tipo de hombre fuerte (el Estado) para mantenerse íntegro. El hombre fuerte puede ser éxitoso sólo si tiene los recursos necesarios. Por ende, para el Estado el asegurar el orden social es, simultaneamente, asegurar su propia reproducción al facilitar la continua acumulación del excedente del cual puede obtener recursos. Es en este sentido que, fundamentalmente, el Estado debe desempeñarse como agente de capital.

\subsection{Negri}

Para desarrollar esta noción del Estado como agente de acumulación del capital me valgo del ensayo de 1967 de Antonio Negri, "Keynes and the Capitalist Theory of the State post-1929". En este artículo Negri se centra en los cambios en el Estado moderno gestionados como respuestas a los cambios en las dinámicas sociales de acumulación capitalista, específicamente en la era de la Gran Depresión. En medio del colapso económico mundial, dice Negri, el "capital ahora tenía que arreglárselas con una clase obrera que se había masificado hasta tal punto que su autonomía tenía que tenerse en cuenta, y que simultáneamente tenía 
que ser reconocida en su potencial subversiva, y aprehendida como elemento decisivo y poder impulsor detrás de cualquier modelo futuro de desarrollo" (12). Este reconocimiento por parte de los líderes políticos del rol intrínseco de la clase obrera en la reproducción y acumulación social "marcó el fin histórico del "Estado de Derecho"' (13), esto es, del entendimiento tradicional del derecho y la política basado en la ciudadanía y los derechos de la propiedad: el "fin de laissez-faire" (13). Marcó, con otras palabras, el fin del despliegue nunca cuestionado de los aparatos represivos del Estado en defensa de las fábricas, las minas y los ferrocarriles de los obreros organizados. Marcó también el inicio del Estado como mediador entre el trabajo y el capital (y así alimentaba las teorías pluralistas y liberales modernas del Estado).

Negri continúa: mientras las demandas de la clase obrera se volvían más asertivas, algunos pensadores, entre ellos John Maynard Keynes, se dedicaron a descubrir una manera de "controlar politicamente esta nueva clase dentro de la maquinaria del sistema" (12). Keynes, y nadie más, percibió que la Ley de Say, la teoría del equilibrio económico natural e inherente, ya no tenía validez, y que el capitalismo estilo laissez-faire ya no podía contener las demandas y las acciones sociales de los trabajadores (21). Al advertir esto, Keynes buscaba descubrir un nuevo camino hacia el futuro a través del cual se pudiese forjar un nuevo equilibrio social y político (21). Así, entendió que tendría que reconstuirse el Estado partiendo del reconocimiento de la clase trabajadora como "caraterística necesaria del sistema al cual el poder estatal tendría que acomodarse" (13). El Estado tendría que "descender en la sociedad civil" (13), penetrar la infraestructura social, regular los salarios y adicionalmente planear la economía, actividades antes prescritas, heréticas en los días de laissez-faire. El Estado, en pocas palabras, se volvería "el centro dirigente para toda actividad económica" (26), continuamente recargando el circuito de capital; se volvería, en una palabra, "el plan" (13). A la clase trabajadora le tendría que pagar lo suficiente para que pudiera consumir lo que se producía, y este salario, habiendo alcanzado alturas nunca jamás conocidas, confundiría y neutralizaría las demandas políticas y la toma de conciencia de la clase - demandas por autonomía política, conciencia de la necesidad del derrocamiento del capital (29-30) - . ${ }^{7}$

7 La intransigencia obrera ante esta oferta tan atractiva convertiría al obrero en bandido en cierto sentido, en no nacional, ubicado simbólicamente, y por ende, literalmente, más allá de la protección del Estado y de hecho, en objeto legítimo de la represión estatal. Negri señala que la violencia contra el obrero se justificaría en términos del "Bien Común, la Voluntad General" (14), esto es, remitiéndose a algo como la idea de la nación en cuyo nombre el Estado actúa. 
Esto, para Negri, es el gran aporte de Keynes: puso al Estado al servicio de la clase obrera, en cierto sentido, para equilibrar y sostener la formación social en su totalidad. En esta instancia, es claro que el Estado es autónomo con respecto a los conflictos entre la clase capitalista (gran parte de la cual veía en el programa de Keynes la clara influencia del bolchevismo). El Estado, sin embargo, se elevaba por encima de las mezquinas riñas internas de la burguesía para asegurar el propio futuro de la formación social. Esto necesitaba un actuar que asegurara la base para la continua acumulación capitalista; implicaba que el Estado actuara como agente del capital como tal.

\subsection{Jameson y Campbell}

¿El Estado como agente del capital como tal? Tal vez. Pero aún se quiere preguntar, ¿qué es? Decir que el Estado es agente del capital deja sin decir exactamente qué, en sentido empírico, es el Estado. Lo que no es, es claro: no es reducible a la burguesía, a la policía, o al Gobierno. La teoría del Estado no ofrece una respuesta suficiente, contentándose con referencias a "un complejo de instituciones", sin señalar una específica. Martin Carnoy, sin ayudar mucho, ha sugerido que el Estado es, simplemente, el "sector público" (3). Yo no puedo ofrecer definiciones exactas o más bien positivistas, pero creo que sí puedo pensar en cómo expresar su efectividad. Para poder hacerlo, consideramos primero el campo de la teoría literaria y específicamente un aporte de Fredric Jameson, y segundo, una contribución del campo creciente pero hasta ahora novedoso de lo que pueden llamarse planteamientos postestructuralistas de las relaciones internacionales. Aquí el autor es un proponente temprano, David Campbell.

En Documentos de cultura, documentos de barbarie, Jameson explica el concepto de modo de producción de Althusser, sosteniendo que debe concebirse como una "causa ausente, puesto que en ningún sitio está presente empíricamente como un elemento [...] sino que es más bien el sistema entero de relaciones entre" $(31)^{8}$ los elementos culturales, ideológicos, legales, y así sucesivamente. De la misma manera, sugiero yo, deberíamos entender el Estado. Quiero decir que el Estado también puede entenderse en cierto sentido como causa ausente, rara - si alguna - vez empíricamente presente como un elemento o una institución en la formación social. No podemos indicar y exclamar "¡Allá está!”. Más bien es la causa analítica (empíricamente ausente pero teóricamente presente) del sistema

El Estado, perversamente, protege a la nación de si misma, y así resulta ser objeto de una devoción más importante que la nación como tal.

8 He tenido que enmendar la traducción para hacerla más fiel al original. 
entero de relaciones entre instituciones que sí son más distinguibles; de esta manera, ejerce un dominio sobre lo social y sirve como agente de la causa ausente superior: el modo de producción, el capitalismo. Es posible, luego, remitirnos al Estado a posteriori, de modo diacrónico. Y semejante mirada diacrónica hace irrelevante la noción de autonomía de los autonomistas. Pues, sean lo que sean las acciones locales y específicas y aparentemente interesadas (es decir, sean lo que sean las acciones supestamente autónomas) del Estado, éstas siempre, con el paso del tiempo, se dejan entrever como acciones que reproducen la acumulación capitalista. $^{9}$

Una perspectiva complementaria la ofrece Campbell. Podemos entender que el Estado no tiene "un estatus ontológico aparte de los varios actos que constituyen su realidad"; que su estatus como presencia soberana en la política global es producto de un "discurso de identidad primaria y estable"; y que la identidad de cualquier Estado particular debe entenderse como "constituida tenuemente en el tiempo ... a través de actos de repetición estilizados" y lograda, "no [por medio de] un acto fundador, sino de un proceso regulado de repetición" (9). ${ }^{10}$

Afirmar que el Estado no tiene estatus ontológico no es afirmar que actos fundamentales como torturar, sembrar terror, hacer guerra (y, más mundanamente, gravar), no existan. El punto es que son actos de este tipo los que prestan realidad al Estado, y es su repetición la que hace manifiesta la existencia y la autoridad del Estado. Que ciertos actos idiosincrásicos del Estado se generalicen en tiempos de crisis debe aprehenderse como el intento sanguinario de suturar la grieta entre ideología y ontología, al intentar el Estado convencerse a sí mismo y a los demás de que es real. Pero sea como sea, el más grande pero más oculto acto a través del cual el Estado suele volver a constituirse es el de refundar las bases de la acumulación capitalista.

\section{El Estado en Chile}

Quiero ahora sustentar lo que seguramente ha sido una discusión algo abstracta con un ejemplo concreto para que se pueda evidenciar en el mundo real lo que he considerado hasta aquí. Desde mi modo de ver, el desarrollo del Estado en Chile sirve para esto; en pocas palabras, el Estado chileno ha tenido que desarrollarse con respecto a un punto de referencia fundamental: el ya establecido sistema capitalista

9 El escándalo del Chavismo es que mientras hubo expropiaciones y cosas parecidas, y el bienestar social se convirtió en bien social, las relaciones básicas de explotación del proceso económico han seguido intactas.

10 Las citas internas son de Judith Butler, mientras la elipsis y los corchetes son de Campbell. 
mundial. Es por esto que el desarrollo en Chile, y en muchas otras partes, ha sido tan problemático. ${ }^{11}$ Sin embargo, esta perspectiva no es la dominante.

Jay Kinsbruner en Chile: A Historical Interpretation (y ver Sater también), ofrece otra perspectiva. Kinsbruner sostiene que la falta de desarrollo en Chile a través de su historia se debe a la elección racional de las élites por el comercio libre. Esta preferencia dejó abierta la puerta para que los capitalistas extranjeros invertieran en las industrias chilenas, dejando como resultado la repatriación de las ganancias y, por ende, poco desarrollo interno. Los capitalistas chilenos preferieron invertir en empresas no relacionadas con la infraestructura y el desarrollo porque su interés no era el progreso de su país sino sus portafolios personales. Entonces, - Kinsbruner explica (de modo exculpatorio) - el desarrollo quedó truncado en Chile como consecuencia de las elecciones estratégicas hechas por los propios chilenos. Por el contrario, en su famoso Capitalismo y subdesarrollo en América Latina, Andre Gunder Frank (ver Loveman para un análisis complementario) sostiene que el subdesarrollo chileno era inevitable gracias a las leyes necesarias e inescapables que gobiernan la acumulación capitalista a escala mundial. Su argumento es que desde el momento en el que la región conocida hoy en día como Chile fue incorporada en el imperio español, su economía ha sido estructurada sobre la base de las exportaciones para suplir y servir las necesidades de la metrópolis.

Mi reconceptualización del Estado permite reconciliar estas dos perspectivas. Aunque Frank no dice mucho sobre el rol directo del Estado, sí observa que "se presentaron oportunidades en que incluso ciertos cambios estructurales dentro del sistema capitalista de Chile podía haber alterado materialmente el curso de la historia del país" (24). Se remite, por ejemplo, al hecho de que Chile no controlaba su economía de nitrato y por ende no incidía en el gasto del superávit generado, un punto que Kinsbruner también observa, pero Frank no hace más que oferecer pistas de un análisis que aclarase las elecciones de las élites chilenas. Kinsbruner, por su parte, al privilegiar la noción de elegir como explicación del subdesarrollo chileno, depende de una noción no problematizada del ser humano como agente racional y libre, dotado de una voluntad autónoma. No

11 Es importante ser claro sobre este punto. Hablar del desarrollo y de la falta de desarrollo es, para algunos, casi un pensamiento criminal. No quiero sugerir que haya -o que haya habidopaíses (completa y perfectamente) desarrollados y otros "primitivos", y mucho menos hoy en día cuando la infraestructura, los sistemas educativos, y la seguridad están en vilo, y la brecha social está más marcada que nunca, en lo que alguna vez se llamó el Primer Mundo. Sin embargo, lo que no se puede negar al respecto es que algunos países - pocos, en fin (Rivero) - pudieron dar la impresión de haberse desarrollado (parecía que todos sus habitantes gozaban de una vida más o menos digna), mientras era bastante obvio que en otros países pocos gozaban de ese privilegio. 
obstante, si no niego que los individuos tienen algún grado de libertad, insisto, claro está, en que el terreno sobre el cual un acto y una elección se hacen está circunscrito. Como lo dice ese viejo refrán marxista, sí hacemos historia pero no en condiciones escogidas por nosotros. Esto quiere decir que las escogencias de los capitalistas chilenos, no como nacionales sino como sujetos de clase determinados dentro de un sistema mundial capitalista, fueron perfectamente racionales, hechas con vista no a lo que necesitaba el país - porque, en el análisis final, ¿qué necesitaba? - sino a lo que les interesaba a ellos mismos. Y su interés personal era incomensurable con el desarrollo interno.

Es aquí donde volvemos al Estado y al asunto de la autonomía. Tarde en el siglo XIX y temprano en el siglo XX hubo unas figuras importantes que sí intentaron apalancar el Estado y modernizar a Chile, llevarlo "a máxima velocidad al siglo XX" (Kinsbruner 112). Estas figuras fracasaron al chocar con una oposición interna e internacional; más que invalidar la noción de autonomía estatal, debería animarnos a preguntar por su signficado preciso. La autonomía del Estado no es la autonomía de sus funcionarios qua funcionarios del Estado; estas personas tendrán distintas e incluso conflictivas lealtades y agendas. La autonomía del Estado es su autonomía como agente estructural que, pese a la voluntad de los funcionarios, debe actuar para preservarse, lo cual exige que asegure el acceso a los recursos de los que depende, que actúe como agente de capital. Para hacer esto debe estar atento a la manera en que funciona el modo de acumulación al nivel local tanto como global: el desarrollo de los individuos y sus iniciativas idiosincrásicas no pueden superar las limitaciones modales; sólo la práctica de una clase internacional podría hacerlo.

Si volvemos rapidamente a Negri lo que quiero decir se aclarará. Como él observa, Keynes se había fijado en que en los países avanzados la productividad del capitalismo había sobrepasado la capacidad de consumo y que, por lo tanto, la demanda - el consumo - tendría que potenciarse. Esto se hizo aumentando el salario o el estándar de vida de la clase obrera. Ahora bien, en un país como Chile, el consumo de la clase obrera no era tan importante porque los cimientos capitalistas de la sociedad chilena no se encontraban en el mercado interno sino en el mundial. Así, ni aumentar el salario ni mejorar el estándar de vida del obrero pudieron, como lo hicieron en otros países, salvar el sistema. En cuanto a las élites chilenas, su consumo no pudo aliviar la depresión por ser tan reducido y por satisfacerse con los bienes de consumo europeos. ${ }^{12}$

12 Como lo dice Frank, "la misma estructura metrópoli-satélite, cuyo desarrollo, en primer lugar, dio existencia a la América Latina que conocemos, creó [...] en estas metrópolis latinoamericanas 
Dicho esto, podemos mencionar por lo menos tres momentos en la historia de Chile en donde vemos al Estado actuando autónomamente como agente de capital pese a la voluntad de los funcionarios. ${ }^{13}$ Primero, lo observamos en el proceso de consolidación de Estado bajo Portales en 1830, que estableció una paz - mas no justicia - interna y condujo al dominio de unas pocas familias que suminstraban recursos básicos al mercado internacional. ${ }^{14}$ Otro momento es la guerra civil de 1891, que puso en vilo la continuidad del Gobierno autocrático en el momento preciso en el que tal Gobierno se constituyó como amenaza a los intereses afianzados. ${ }^{15}$ Un tercer momento es el período alrededor de la presidencia

$[\ldots]$ intereses que indujeron a sus grupos dirigentes a satisfacer por medio de importaciones gran parte de su concentrada demanda de consumo" (37). Y sigue: "Esta estructura conspiró también contra la inversión por aquéllos del excedente económico apropiado de sus compatriotas, en fábricas para su propio consumo o para la exportación, y mucho menos, por supuesto, para el consumo de los expropiados" (37).

13 Espero que el lector perdone la metodología expositiva escogida aquí. Los detalles quedan relegados a las notas de pie para no distraerlo del argumento principal. Se dejan para otro momento consideraciones del pasado reciente por miedo a que todavía no tengamos la distancia suficiente para poder decir algo con certeza.

14 Como en gran parte del continente, los años 1810-1829 en Chile, en la lucha por la independencia, pueden describirse acertadamente como caóticos. Desde el año 1810 se había proclamado la independencia formal pero fuerzas realistas partiendo desde Perú se impusieron de nuevo en 1814 como parte de la llamada reconquista. En 1817 una invasión patriótica se armó desde Argentina y volvió a liberar al país; Bernardo O'Higgins se instaló como director supremo. $\mathrm{Al}$ atacar (y no cultivar) defensores potenciales - la Iglesia, los terratenientes, las provincias (cuyos líderes no estaban del todo dispuestos a someterse al principio nacional) - y al ser difamado en Chile por sus conexiones argentinas, O'Higgins se encontró el objetivo de una rebelión que concluyó cuando renunció en enero de 1823.

Durante los próximos siete años hubo varios intentos de gobernar y varias constituciones fueron elaboradas y abandonadas. Como lo resume Kinsbruner, "faltaba la estabilidad que sintonizara con los intereses fundamentales de la burguesía chilena" (52). Luego, entre 1829 y 1830, una coalición conservadora - los pelucones- consolidó su poder bajo Portales, repudiando los experimentos liberales del pasado reciente. "Su demanda estridente y sencilla era por un gobierno fuerte y el fin del desorden" (Collier y Sater 50). Esta coalición, que gobernaría de una u otra forma durante los próximos 27 años, garantarizaría el orden y la protección de la parte de la población que importaba (las élites y los terratenientes). De esta manera demostró su utilidad social y recibió lo que necesitaba para poder consolidarse como el Estado.

15 El presidente durante la guerra, José Manuel Balmaceda, instalado en 1886, quiso utilizar el Estado para un desarrollo ambicioso. Según Kinsbruner, "quiso gestionar mejorías internas, estimular y proteger la industria local, mejorar la educación, aumentar salarios, reformar el sistema tributario, en fin, llevar a Chile a máxima velocidad al siglo XX" (112). Aquí puede plantearse la siguiente pregunta: ${ }_{\mathrm{i}}$ Semejantes acciones habrían cumplido los criterios de la utilidad social? Individuos distintos, clases distintas y diferentes fracciones de clases responderían de manera distinta. ¿Es útil que un labriego sepa leer, sumar? Si a esto sumamos el hecho de que para financiar sus propuestas Balmaceda planeaba nacionalizar la industria de 
de Alessandri y la Constitución de 1925, que de una manera más o menos formal hizo nacionales de los miembros de la clase obrera (pero no de la clase campesina). Entonces, aunque el programa de Balmaceda de 1886 y la plataforma de Alessandri de 1920 eran keynesianos avant la lettre, eran, más aún, innecesarios en cada caso desde el punto de vista de la estructura, el modo de producción, y en consecuencia, eran imposibles de realizar bajo la razón capitalista. ${ }^{16}$ En cada caso, el drama del Estado en contra de sí mismo terminaba en la victoria del mismo Estado, que seguía organizando, mutatis mutandis, la extracción del excedente y la acumulación como siempre.

Por supuesto, 1973 es único en su significado particular y desafortunadamente se ofrece como el sustento más convincente del presente argumento. El golpe contra Allende fue más que un ataque brutal por parte del Estado contra el Estado en nombre de la nación; fue la afirmación horrorosa del poder apropiado del Estado contra el poder estatal renegado (anti-capitalista), inapropiado. El hecho de que todavía hay miles que recuerdan el futuro (socialista) de Chile y promueven la idea de un Chile socialista por venir, sólo hace más evidente la relevancia de la distinción con la que empezamos, aquélla entre la subjetividad nacional y estatal.

nitratos y el sistema de ferrocarriles, el asunto se vuelve complejo. Es más, propuso un banco nacional, el cual habría infringido las ganancias y los privilegios de la banca privada. Resulta que suficientes capitalistas chilenos y banqueros, apoyados por unas secciones de los mineros (que odiaban a Balmaceda por haber aplastado sus huelgas en 1890), junto con capitalistas extranjeros, aliados con el congreso y la marina, decidieron que el plan de Balmaceda era totalmente inaceptable, y se rebelaron. Estalló una guerra civil y se dieron 10,000 bajas. Las fuerzas rebeldes cantaron la victoria y Balmaceda se suicidó. Lo importante - para el presente argumento- es que la guerra contra el propio Estado terminó con con la victoria del Estado ameno a las necesidades del capitalismo global, como su agente.

16 Haciendo campaña con una plataforma que lo situaba entre la decadencia de la oligarquía y la anarquía de los obreros, Arturo Alessandri Palma ganó la presidencia en 1920. Había prometido un plan de desarrollo ambicioso y los temas tocados en la campaña dejaron atrás el terreno tradicional de la política, tal que la "contienda dejaba de ser un asunto político para convertirse en uno social" (Piñera Echenique, 147). Los comentaristas contemporáneos de las clases respetables sonaban la alarma sobre la candidatura. En Sucesos, un semanario sobre la sociedad y la política chilena, el coordinador A. Sotomayer escribió: "Lo sentimos mucho. La candidatura Alessandri va a provocar una lucha enconada, una agitación violenta. El país sufrirá las consecuencias. Un candidato apasionado no es el hombre sereno y patriota que necesita la nación" (4.29.20). Casi dos meses después le está dando a Alessandri el papel de bolchevique, su oponente "un demócrata moderado, tradicional" (6.24.20). Igual, ganó Alessandri. Poco después, en una entrevista con el líder de fuventud Aliancista, el triunfo de Alessandri es visto como la evidencia de que "ha llegado el momento del gobierno del pueblo, por el pueblo, y para el pueblo" (7.15.20). Sin embargo, Alessandri no pudo avanzar con su programa en el Congreso, todavía bajo el control de las élites tradicionales. El Estado haría lo suyo, como siempre. 


\section{Conclusión}

Como conclusión, entonces, planteo que el descubrimiento de que las naciones son comunidades imaginadas ha precipitado en los estudios literarios y en otros ámbitos mucha investigación sobre cómo las formas culturales inciden en la construcción de una nación y sus sujetos (Skurski; Sommer). Adicionalmente, el canon literario ya no puede ser entendido como una recolección arnoldiana de lo mejor sabido y dicho de un lugar y de una gente; más bien, se entiende como un modo de validar y promocionar identidades "nacionales" que no son universales - disponibles para todos-sino particulares: identidades raciales, de clase, de género, políticas y politizadas y así sucesivamente. Pero si el análisis crítico de la producción literaria ha avanzado en algún grado en desmitificar la relación generadora entre literatura y sujetos nacionales, le falta todavía enfocarse en la misma relación entre literatura y Estado. Debido a que vivimos, de verdad, en un sistema capitalista mundial, se puede decir sin temor a equivocarse que la mayoría de los sujetos nacionales son, a la vez, sujetos del Estado, sujetos sometidos al y del Estado y toda su fiereza. ¿ ¿De dónde vienen? ¿Cómo se constituyen? Quizas el estudio de la literatura puede proveer algunas respuestas.

\section{Obras citadas}

Althusser, Louis. "Ideología y aparatos ideológicos de Estado". Ideología: un mapa de la cuestión. Coord. Slavoj Zizek. Buenos

Aires: Fondo de Cultura Económica, 2005. 115-55.

- La revolución teórica de Marx. México: Siglo XXI Editores, 1968.

Anderson, Benedict. Comunidades imaginadas. Reflexiones sobre el origen y difusión del Nacionalismo. México: Fondo de Cultura Económica, 1993.

Appadurai, Arjun. Modernity at Large. Cultural Dimensions of

Globalization. Minneapolis: University of Minnesota Press, 1996.

Arendt, Hannah. "Communicative Power". Power. Ed. Steven Lukes.

New York: New York University Press, 1986. 59-74.

Bourdieu, Pierre. Cosas Dichas. Barcelona: Gedisa, 1993.

Campbell, David. Writing Security: United States Foreign Policy and the

Politics of Identity. Minneapolis: University of Minnesota Press, 1992.

Carnoy, Martin. The State and Political Theory. Princeton:

Princeton University Press, 1984.

Collier, Simon y Peter Sater. A History of Chile, 1808-1994.

Cambridge: Cambridge University Press, 1996.

Rivero, Oswaldo de. Los Estados inviables: no-desarrollo y supervivencia en el Siglo XXI. Madrid: Catarata, 2010. 
Evans, Peter R., Dietrich Rueschmeyer y Theda Skocpol, eds. Bringing the State Back In. Cambridge: Cambridge University Press, 1985.

Frank, Andre Gunder. Capitalismo y subdesarrollo en América Latina. México: Siglo XXI, 1978.

Gramsci, Antonio. Cuadernos de la cárcel. México: Juan Pablos Editor, 1975.

Jameson, Fredric. Documentos de cultura, documento de barbarie. La narrativa como acto socialmente simbólico. Madrid: Visor, 1989.

Kinsbruner, Jay. Chile. A Historical Interpretation. New York: Harper and Row, 1973.

Lenin, Vladimir Ilich. El Estado y la Revolución. La doctrina marxista del Estado y las tareas del proletariado en la Revolución. Moscú: Editorial Progreso, 1978.

Loveman, Brian. Chile. The Legacy of Hispanic Capitalism.

New York: Oxford University Press, 1979.

Mann, Michael. States, War and Capitalism. Studies in Political Sociology. Oxford: Blackwell, 1988.

Marx, Carlos and Friedrich Engels. Manifiesto del Partido Comunista. Mataró: El Viejo Topo, 2005.

Miliband, Ralph. The State in Capitalist Society. London: Weidenfeld \& Nicolson, 1969.

Negri, Antonio. "Keynes and the Capitalist Theory of the State". Revolution Retrieved: Writings on Marx, Keynes, Capitalist Crisis and New Social Subjects (1967-83). London: Red Notes, 1988. 5-42.

Negri, Antonio and Michael Hardt. Imperio. Buenos Aires: Paidos, 2002.

Piñera Echinque, Sebastián. Los 100 eventos de la historia de Chile. Santiago: Sociedad Editorial los Andes, 1990.

Poulantzas, Nicos. Estado, poder, y socialismo. México: Siglo XXI, 2005.

Sater, William F. Chile and the United States: Empires in Conflict. Athens: University of Georgia Press, 1996.

Skocpol, Theda. "Bringing the State Back In: Strategies of Analysis in Current Research." Bringing the State Back In. Evans, Peter R., Dietrich Rueschmeyer y Theda Skocpol (eds). Cambridge: Cambridge University Press, 1985: 3-37.

Skurski, Julie. "The Ambiguities of Authenticity in Latin America: Doña Bárbara and the Construction of National Identity". Poetics Today 15 winter 1994: 605-38.

Sommer, Doris. Ficciones fundacionales. Las novelas nacionales de América Latina. Bogotá: Fondo de Cultura Económica, 2004.

Sotomayer, A. "Potpourri". Sucesos (Chile) (fechas en texto). N. pag.

Tilly, Charles. "Guerra y construcción del estado como crimen organizado." Revista Académica de Relaciones Internacionales Nov. 2006.

Wallerstein, Immanuel. The CapitalistWorld-Economy. Cambridge: Cambridge University Press, 1979.

Weber, Max. "El político científico". Madrid: Alianza, 1979. 